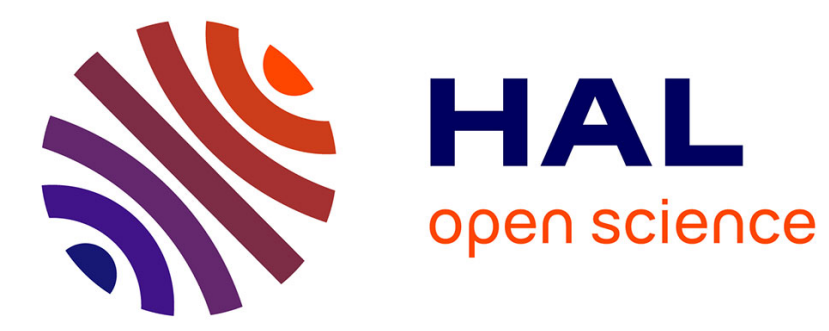

\title{
Treatment of polymer surfaces: development of an industrial plasma process
}

\author{
B. Mutel, O. Dessaux, P. Goudmand, F. Luchier
}

\section{To cite this version:}

B. Mutel, O. Dessaux, P. Goudmand, F. Luchier. Treatment of polymer surfaces: development of an industrial plasma process. Revue de Physique Appliquée, 1990, 25 (10), pp.1019-1023. 10.1051/rphysap:0199000250100101900 . jpa-00246268

\section{HAL Id: jpa-00246268 https://hal.science/jpa-00246268}

Submitted on 1 Jan 1990

HAL is a multi-disciplinary open access archive for the deposit and dissemination of scientific research documents, whether they are published or not. The documents may come from teaching and research institutions in France or abroad, or from public or private research centers.
L'archive ouverte pluridisciplinaire HAL, est destinée au dépôt et à la diffusion de documents scientifiques de niveau recherche, publiés ou non, émanant des établissements d'enseignement et de recherche français ou étrangers, des laboratoires publics ou privés. 


\title{
Treatment of polymer surfaces : development of an industrial plasma process
}

\author{
B. Mutel, O. Dessaux, P. Goudmand and F. Luchier \\ Laboratoire de physicochimie de l'énergétique et des plasmas, Université des Sciences et Techniques de Lille, \\ Flandres Artois, 59655 Villeneuve d'Ascq Cedex, France
}

(Received 26 September 1989, revised 28 February 1990, accepted 3 July 1990)

\begin{abstract}
Résumé. - Un procédé de traitement par plasma froid différé d'azote (PFDN) de grande extension spatiale en volume est mis au point afin d'améliorer les propriétés adhésives de surfaces plastiques. L'enceinte réactionnelle a un volume de 160 litres. La concentration en azote atomique, principale espèce réactive du $\mathrm{PFDN}$, est homogène dans tout le réacteur et est approximativement égale à $8 \times 10^{16}$ atomes.cm ${ }^{-3}$. Ce réacteur permet d'obtenir un traitement de surface uniforme, même pour des objets de géométrie complexe. Ce procédé, testé en production par une industrie électronique, a conduit à une amélioration du coût d'un facteur 2,5 par rapport aux résultats obtenus avec un traitement chimique.
\end{abstract}

\begin{abstract}
A cold remote nitrogen plasma (CRNP) equipment is developed in order to improve adhesion quality of plastic surfaces. The volume of the reaction chamber is 160 litres. The concentration of atomic nitrogen, which is the main reactive species of the CRNP is homogeneous in the whole reactor and is about $8 \times 10^{16}$ atoms.cm ${ }^{-3}$. An uniform surface treatment of pieces with complex shapes is obtained. This process, tested in production by an electronic industry leads to an economic cost divided by 2.5 in comparison with chemical treatment.
\end{abstract}

\section{Introduction.}

Polymers are of considerable importance in many industrial, biomedical and technological applications. But, modification of surface properties is often required while leaving the overall quality of this material unchanged.

For the ten past years, surface modification by exposure to a plasma has received considerable attention. This process is simple to carry out and can modify the physical, chemical and electrical properties of material surface. The extend of the modification is directly related to the characteristics of the plasma discharge parameters and plasma gas composition.

The aim of this work is to develop an industrial plasma process to increase adhesion properties of polymers surfaces towards others substances. Indeed, it has been shown [1] that plasma affects all parameters involved in the adhesion of material (wettability, adsorption, polarity, fixation of ions, free radicals or excited species).
In a previous paper [2], we gave evidence for the rational use of a low pressure microwave postdischarge plasma to increase the adhesivity of polypropylene in order to improve the adhesion of epoxy resin used to protect electronic components in their boxes. A short time of treatment $(1 \mathrm{~min})$ with nitrogen plasma doped with fluorine compound $\left(\mathrm{NF}_{3}\right)$ leads to a consumption of energy divided by 700 and to an economic cost divided by 4 in comparison with industrial chemical process. Moreover, adhesive qualities of the treated surfaces remained excellent even after several months $(>12)$ or accelerated aging. This study was carried out with a 2 litres cylindrical pyrex reactor.

Industrial applications of this process imply an uniform and efficient treatment of large objects with complicated shapes requiring large reactor capacities (several hundred litres). The aim of the present paper is to develop a 160 litres reactor with a concentration of reactive species which has to be homogeneous and maximum within the reactor. Otherwise, rules about industrial use of fluorine 
compounds are such that it is necessary to develop a plasma treatment equipment working without fluored gases.

\section{Experimental conditions.}

2.1 EXPERIMENTAL DEVICE. - A schematic diagram of the experimental set up is shown in figure 1 . Nitrogen flow, created by a continuous pumping is excited from an electrodeless discharge by means of a microwave generator $(2450 \mathrm{MHz})$. The discharge cavity, previously described [3], is a rectangular one, operating in the TE 102 mode. The discharge is produced in a quartz tube (32 $\mathrm{mm}$ inner diameter) which is coupled (either in position $《 a \|$ or $« b \|)$ to the 160 litres reactor. After the discharge, two zones can be observed :

- the first, located near the discharge point, appears like a pink afterglow. In this zone, the concentration of ionic species is not negligible [4, p. 49]. It has been shown that this afterglow is not efficient to create adhesion properties on polymer surfaces [5] ;

- the second appears like a yellow afterglow expanding downstream the previous zone. It is characterized by a very low charged particules concentration and an important thermodynamic non-equilibrium [6]. This last zone is then denoted by CRNP (Cold Remote Nitrogen Plasma).

The treatment chamber is a pyrex cylindrical reactor which is $1.2 \mathrm{~m}$ long. Its inner diameter is equal to $0.45 \mathrm{~m}$.

Gaseous flow is controlled with a mass flow controller and pressure in the reactor is measured with a Pirani gauge. Dynamic flow is created by a roots pumping system (CP serie from Alcatel) which nominal pumping speed is $250 \mathrm{~m}^{3} / \mathrm{h}$. This system is equipped with a variable speed roots blower giving a fully automatic regulation of the pressure in the reactor.

2.2 EVAluation OF THE CRNP REACTIVITY.Atomic nitrogen in its ground state, $\mathrm{N}\left({ }^{4} \mathrm{~S}\right)$, is the

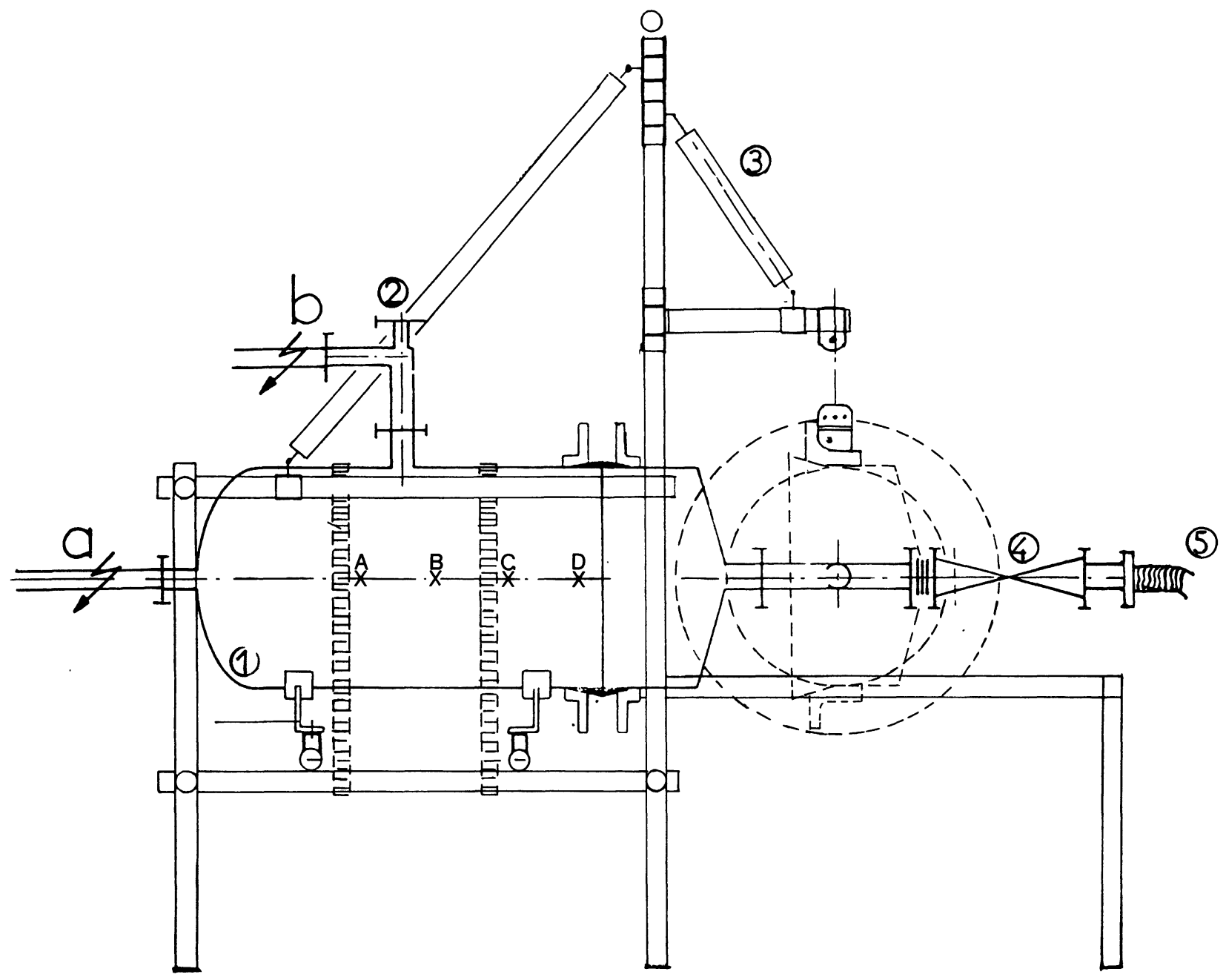

Fig. 1. - Experimental set up : (1) pyrex reactor (160 litres), (2) Pirani gauge, (3) door's aperture system with movable bracket, (4) tap, (5) towards to the pump. 
main specy of a CRNP ; so, in a first approximation, its reactivity is followed from the evolution of the concentration of this specy (denoted by $[\mathrm{N}]$ ) within the reactor.

2.2.1 Spectroscopic method. - Working pressure in the reactor is around $5 \mathrm{hPa}$. Under these conditions, the intensity of the $\mathrm{B}^{3} \Pi_{\mathrm{g}}-\mathrm{A}^{3} \Sigma_{\mathrm{u}}^{+}$transition of $\mathrm{N}_{2}$, responsible for the typical yellow afterglow of the CRNP, is proportional to $[N]^{2}$ [7]. So, the evolution of [N] may be followed from the total intensity of the 12-8, 11-7 and 10-6 bands of the $\mathrm{B}^{3} \Pi_{\mathrm{g}}-\mathrm{A}^{3} \Sigma_{\mathrm{u}}^{+}$transition of $\mathrm{N}_{2}$. This intensity (denoted by $I$ ) is measured by a conventional spectroscopic device. The monochromator Bausch and Lomb equipped with a 1221 lines/mm grating blazed at $650 \mathrm{~nm}$ is connected to a RCA 1 P28 photomultiplier coupled with a potentiometric recorder. The observation axis is perpendicular to the pyrex reactor and is moved in parallel to the axis of the reactor. The observation zone is restricted to the cylindrical part. A screen allows to eliminate stray light from the discharge. The entrance slit of the monochromator is ajusted against the wall of the pyrex reactor and is moved in parallel to the axis of the reactor in positions A, B, C and D (Fig. 1). The aim of this work is not to obtain accurate values of $[N]$ at given positions in the reactor but to test the homogeneity of $[\mathrm{N}]$ in carrying out average measurements on broad zones of plasma.

2.2.2 Chemical method. - The previous spectrometric method has an advantage: there is no interference with the process occurring in the reactor. But, it allows to get only a relative value of $[\mathrm{N}]$. The absolute value of $[\mathrm{N}]$ is established by a NO titration. This method turns to account the rapid gas phase reaction between $\mathrm{N}\left({ }^{4} \mathrm{~S}\right)$ and NO :

$$
\mathrm{N}\left({ }^{4} \mathrm{~S}\right)+\mathrm{NO}\left(\mathrm{X}^{2} \Pi\right) \rightarrow \mathrm{N}_{2}\left(\mathrm{X}^{1} \Sigma_{\mathrm{g}}^{+}\right)+\mathrm{O}\left({ }^{3} \mathrm{P}\right) .
$$

When the flow of NO $\left(Q_{\mathrm{NO}}\right)$ is smaller or approximately equivalent to that of atomic nitrogen, $\mathrm{NO}$ is exclusively destroyed by reaction (1). The end point is determined from the well-known afterglow colorations modifications [4] typical of the several steps of the N-NO reactions. NO is introduced according to the axis of the reactor by means of a moving injector which can be located in positions A, B, C and D (Fig. 1).

\section{Experimental results.}

3.1 RESEARCH OF A HOMOGENEOUS CONCENTRATION OF $\mathrm{N}\left({ }^{4} \mathrm{~S}\right)$. - All experiments are performed for a given transmitted microwave power $(P=0.75 \mathrm{~kW})$ and a given distance between the discharge and the reactor $(d=1 \mathrm{~m})$.

When the discharge is in position «a " (Fig. 1), it is not possible to obtain a homogeneous CRNP in the whole reactor, whatever the flow may be. When the flow rate is upper than $16 \mathrm{l} / \mathrm{min}$, a strong turbulent flow occurs. On the other hand, when the flow rate is lower than $12 \mathrm{l} / \mathrm{min}$, the yellow afterglow does not occupy the whole reactor and is strongly perturbed by the ionic species of the pink afterglow. When the flow rate is ranging from 12 to $16 \mathrm{\ell} / \mathrm{min}$, the yellow afterglow occupies the whole reactor, but remains perturbed by the pink afterglow.

A $90^{\circ}$ elbow, settled between the discharge tube (in position " a ") and the reactor allows to cut out the pink afterglow, but the homogeneity of the yellow afterglow (controlled from $I$ ) is not get whatever the flow may be.

A discharge in position $" \mathrm{~b}$ " with a $90^{\circ}$ elbow between the discharge tube and the reactor leads to a rather homogeneous yellow afterglow in the whole reactor for nitrogen flow ranging from 12 to $16 \mathrm{l} / \mathrm{min}$. Table I gives results of a space study of [N] (given in arbitrary units) obtained from $I$ measurement for a nitrogen flow equal to $12 \mathrm{l} / \mathrm{min}$. The homogeneity of the CRNP is evidenced $(9 \%)$ as well as a right reproductibility of $[\mathrm{N}](<4 \%)$.

Table I. - Space study of [N] (arbitrary units). $P=0.75 \mathrm{~kW} ; d=0.63 \mathrm{~m} ; Q_{\mathrm{N} 2}=12 \ell / \mathrm{min}$. Observation zones are located in figure 1 .

\begin{tabular}{|c|c|c|c|c|c|c|}
\hline Observation & A & B & C & D & $k[\mathrm{~N}]\rangle$ & $\frac{\Delta[\mathrm{N}]}{[\mathrm{N}]}$ \\
\hline 1 & 5.20 & 5.48 & 5.57 & 5.48 & 5.43 & $6.8 \%$ \\
\hline 2 & 5.10 & 5.48 & 5.57 & 5.38 & 5.38 & $8.7 \%$ \\
\hline 3 & 5.29 & 5.57 & 5.74 & 5.48 & 5.52 & $8.1 \%$ \\
\hline$\langle[\mathrm{N}]\rangle$ & 5.19 & 5.51 & 5.62 & 5.45 & & \\
\hline$\frac{\Delta[\mathrm{N}]}{[\mathrm{N}]}$ & $3.7 \%$ & $1.6 \%$ & $3.0 \%$ & $1.8 \%$ & & \\
\hline
\end{tabular}

3.2 RESEARCH OF A HOMOGENEOUS AND MAXIMUM CONCENTRATION OF $\mathrm{N}\left({ }^{4} \mathrm{~S}\right)$. - For $P=0.75 \mathrm{~kW}$ and $d=1 \mathrm{~m}$, a homogeneous concentration of $\mathbf{N}\left({ }^{4} S\right)$ is obtained with a discharge in position " $\mathrm{b}$ " and a nitrogen flow $Q_{\mathrm{N} 2}=12 \mathrm{l} / \mathrm{min}$. The influences of $P$ and $d$ are now studied in order to get a maximum $[\mathrm{N}]$ value.

When $d$ increases, $[\mathrm{N}]$ decreases: for $Q_{\mathrm{N} 2}=12 \mathrm{l} / \min$ and $P=0.75 \mathrm{~kW},[\mathrm{~N}]$ decreases by $5 \%$ when $d$ increases from 0.63 to $1.08 \mathrm{~m}$, but remains homogeneous in the whole reactor. The distance between the discharge and the reactor cannot be lower than $0.63 \mathrm{~m}$ because of the size of the resonant cavity, and with this cavity, the mini- 
mum incident power allowing the creation of a plasma in this reactor is equal to $0.70 \mathrm{~kW}$.

For $Q_{\mathrm{N} 2}=12 \ell / \mathrm{min}$ and $d=0.63 \mathrm{~m},[\mathrm{~N}]$ increases when $P$ increases and is homogeneous in the whole reactor as long as $0.70 \leqslant(P, \mathrm{~kW}) \leqslant 0.75$. For $P>0.75 \mathrm{~kW},[\mathrm{~N}]$ is much higher for the observation zone in position $B$ (which corresponds to the injection zone of the CRNP in the reactor), but remains homogeneous for the three other positions. Figure 2 shows the variation of [N] (observation zone in position C) versus $P$.

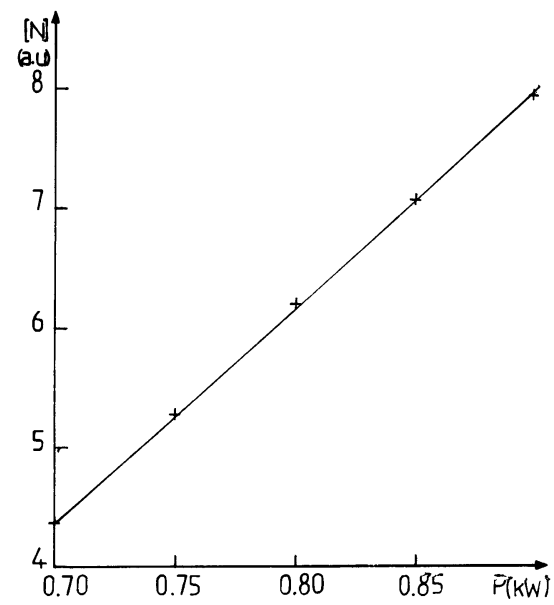

Fig. 2. - Evolution of [N] (observation zone in position C) versus transmitted microwave power $(P, \mathrm{~kW})$.

So, experimental conditions to get a homogeneous CRNP in this 160 litres pyrex cylindrical reactor with $0.45 \mathrm{~m}$ inner diameter are :

$$
P=0.75 \mathrm{~kW} ; \quad Q_{\mathrm{N} 2}=12 \mathrm{l} / \mathrm{min} ; d=0.63 \mathrm{~m} .
$$

3.3 ABSOLUTE MEASUREMENT OF THE CONCENTRATION OF $\mathrm{N}\left({ }^{4} \mathrm{~S}\right)$. - For $Q_{\mathrm{N} 2}=12 \ell / \mathrm{min}$ and $d=0.63 \mathrm{~m}$, a spectroscopic measurement of $I$ and a NO titration are simultaneously carried out in order to evaluate $[\mathrm{N}]$ and to test the homogeneity of the CRNP by this second method.

Measurements are carried out in three zones along the reactor $(A, C, D)$ and for different $[N]$ obtained from variations of microwave power. For $P>0.75 \mathrm{~kW},[\mathrm{~N}]$ is higher in B (see Sect. 3.2), so, we don't take into account this zone. The flow of NO equivalent to that of atomic nitrogen is denoted $Q_{\text {NO }}$. A good reproductibility of measurements are obtained for each zone. Average values are shown in table II which gives evidence for a good agreement between [N] deduced from $Q_{\mathrm{NO}}$ and $I$ :

$$
I^{1 / 2} / Q_{\mathrm{NO}}=\text { constant within } 4.5 \% \text {. }
$$

This study allows to evaluate that atomic nitrogen concentration in experimental conditions previously
Table II. - Determination of [N] and correlation between NO titration and spectroscopic measurements. $Q_{\mathrm{N} 2}=12 \ell / \mathrm{min} ; d=0.63 \mathrm{~m} ; I$ and $Q_{\mathrm{NO}}$ values are average measurements realized in zones $A$,

\begin{tabular}{|c|c|c|c|c|}
\hline$P(\mathrm{~kW})$ & $I$ (a.u.) & $\underset{(\ell / \mathrm{min})}{Q_{\mathrm{NO}}}$ & $\begin{array}{c}{[\mathrm{N}]} \\
(\text { atoms.cm } \\
-3\end{array}$ & $I^{1 / 2} / Q_{\mathrm{NO}}$ \\
\hline 0.70 & 19 & 0.031 & $6.94 \times 10^{16}$ & 141 \\
\hline 0.75 & 28 & 0.036 & $8.06 \times 10^{16}$ & 147 \\
\hline 0.80 & 40 & 0.044 & $9.85 \times 10^{16}$ & 146 \\
\hline 0.85 & 51 & 0.049 & $10.97 \times 10^{16}$ & 146 \\
\hline 0.90 & 63 & 0.055 & $12.32 \times 10^{16}$ & 144 \\
\hline
\end{tabular}
$C, D$.

described to produce a homogeneous CRNP is about to $8 \times 10^{16}$ atoms.cm ${ }^{-3}$, and confirms the homogeneity of the CRNP.

3.4 ConClusion. - It is possible to produce a homogeneous 160 litres cold remote nitrogen plasma which atomic nitrogen concentration is about $8 \times 10^{16}$ atoms.cm ${ }^{-3}$. Experimental conditions to obtain such a plasma are : $P=0.75 \mathrm{~kW}, Q_{\mathrm{N} 2}=$ $12 \mathrm{l} / \mathrm{min}, d=0.63 \mathrm{~m}$. The discharge has to be produced in a quartz tube which is coupled with the cylindrical reactor by means of a $90^{\circ}$ elbow located on the length of the cylinder (Fig. 1, position « $\mathrm{b} »)$.

\section{An industrial exemple.}

The process is developed in industrial conditions for a manufacture of electronic components: RIFA S.A. Flame retardant polypropylene (DG 687 from Cole Plastics Limited) boxes used to the production of capacitors are treated by CRNP in order to improve their adhesive properties [2]. With the 160 litres reactor, it is possible to treat simultaneously 1000 boxes. In first approximation, the creation of adhesive qualities on plastic surfaces is supposed to be in relation with the reactivity of the CRNP. So, operating conditions selected are those described in section $3 \quad\left(P=0.75 \mathrm{~kW}, \quad Q_{\mathrm{N} 2}=\right.$ $12 \mathrm{l} / \mathrm{min}, d=0.63 \mathrm{~m}$ ). The CRNP penetration is so efficient that it can easily go through apertures in the micron range and the efficiency of the process remains unaltered when some or 1000 boxes are inside the reactor.

4.1 Previous Cleaning. - With fluored nitrogen plasma doped with $2 \% \mathrm{NF}_{3}$, it is not necessary to degrease pieces before treatment. But, with a CRNP, this step is necessary to avoid an in- 
homogeneity of adhesive properties and non reproductible results. Five solvent agents are tested : for each of them, boxes are degreased (before CRNP treatment) by ultrasonic bath during 5 minutes at the ambient temperature. Then, they are dried in the air during 24 hours.

After CRNP treatment of these degreased boxes, adhesion quality is controlled by traction tests carried out by Rifa S.A. Whatever the place of the sample in the reactor, homogeneous adhesive properties of the surface are evidenced. For time of CRNP treatment lower than 15 minutes, the relative efficiency of cleaning agent is tested. It follows the sequence :

trichloroethane $>$ ethanol $>$ freon $>$

$$
>\text { methanol }>\text { detergent } \text {. }
$$

For a time of treatment equal to 5 minutes, trichloroethane is the only agent which gives a CRNP treatment as efficient as the chemical treatment. Moreover, this product has the advantage to be industrially allowed.

In usual stock conditions, time between cleaning and treatment has to be shorter than 8 days. Otherwise a new cleaning is necessary to get a good adhesion quality.

4.2 COST FACTORS. - Taking into account a thermic yield equal to $80 \%$, energy cost of chemical treatment is evaluated to $189000 \mathrm{~kJ}$ for 1000 boxes, while the CRNP treatment during 5 minutes costs $1180 \mathrm{~kJ}$ for 1000 boxes (including ultrasounds cleaning). So, in comparison with chemical treatment, energy cost is divided by 160 .

Taking into account operating cost and amortization, economic cost is divided by 2.5 . This saved money allows a pay-back of the investment within one year.

\section{Conclusion.}

A CRNP is developed in order to improve adhesion quality of plastic surfaces. This reactor which volume is equal to 160 litres allows the improvement of adhesive properties of components with complex shapes. During the treatment, the typical colour of the plasma can serve as an indicator of the quality of the CRNP. The system involves an intermittent vacuum process, and care have to be taken for integration into a production line. But, this is no significant obstacle since operating pressure (1$5 \mathrm{hPa}$ ) are reached very rapidly (within about 1 to 2 min with the described device) and process times are in the range of several minutes, with variation according to materials (between 5 and $15 \mathrm{~min}$ ). This process, tested by an electronic industry, leads to an economic cost divided by 2.5 in comparison with chemical treatment usually used. Moreover, the lifetime of treated surfaces being longer than one year, this is an advantage for marketing of treated products.

Chemical reactions taking place at surface or interface are an extremely complex phenomenon. The chemical and morphological nature of a surface plays an important role in the surface reaction. So, methods enabling selective analysis of specific surface groups are very useful to establish a correlation with the modification of surfaces properties. The analysis of functional groups on polypropylene surfaces by XPS, IR and HREELS are now in progress.

\section{Acknowledgments.}

The authors would like to thank RIFA S.A. for their financial support and for providing test facilities and personnel towards the success of this process.

\section{References}

[1] Boenig H. V., Fundamentals of plasma chemistry and technology, Lancaster, PA Technonic Pub, Co (1988).

[2] Mutel B., Dessaux O., Goudmand P., Grimblot J., CARPEnTIER A., SZARZYNSKI S., Revue Phys. Appl. 23 (1988) 1253.

[3] Mutel B., Thèse d'Etat $n^{\circ} 704$, Lille, 1986.

[4] Wright A. N., Winkler C. A., Active Nitrogen, Ed. by E. M. Loebel (Academic Press, New York) 1968.
[5] Dessaux O., Communication au carrefour Innovelect, Lille, 1989.

[6] Mutel B., Bridoux M., Crunelle-Cras M., DesSaux O., Grase F., Goudmand P., Moreau G., Chem. Phys. Lett. 2, 3 (1984) 290.

[7] Mutel B., Thèse $3^{\mathrm{e}}$ cycle, $\mathrm{n}^{\circ} 919$, Lille, 1981. 